\title{
Blood glucose concentration and risk of pancreatic cancer: systematic review and dose-response meta-analysis
}

\author{
@() $\Theta$ OPEN ACCESS
}

\author{
Wei-Chih Liao assistant professor ${ }^{12}$, Yu-Kang Tu associate professor ${ }^{2}$, Ming-Shiang Wu professor ${ }^{1}$, \\ Jaw-Town Lin professor ${ }^{3}$, Hsiu-Po Wang professor ${ }^{1}$, Kuo-Liong Chien professor $^{12}$
}

'Department of Internal Medicine, National Taiwan University Hospital, National Taiwan University College of Medicine, 7 Chang Shan South Road, Taipei 100, Taiwan; ${ }^{2}$ Institute of Epidemiology and Preventive Medicine, National Taiwan University, 17 Hsu Chow Road, Taipei 100, Taiwan; ${ }^{3}$ School of Medicine, Fu Jen Catholic University, 510 Zhongzheng Road, New Taipei City 242, Taiwan

\begin{abstract}
Objective To evaluate potential linear and non-linear dose-response relations between blood glucose and risk of pancreatic cancer.

Design Systematic review and dose-response meta-analysis of prospective observational studies.

Data sources Search of PubMed, Scopus, and related reviews before 30 November 2013 without language restriction.

Eligibility criteria Prospective studies evaluating the association between blood glucose concentration and pancreatic cancer. Retrospective and cross sectional studies excluded to avoid reverse causality.

Data extraction and synthesis Two reviewers independently extracted relevant information and assessed study quality with the

Newcastle-Ottawa scale. Random effects dose-response meta-analysis was conducted to assess potential linear and non-linear dose-response relations.

Results Nine studies were included for analysis, with a total of 2408 patients with pancreatic cancer. There was a strong linear dose-response association between fasting blood glucose concentration and the rate of pancreatic cancer across the range of prediabetes and diabetes. No non-linear association was detected. The pooled rate ratio of pancreatic cancer per $0.56 \mathrm{mmol} / \mathrm{L}(10 \mathrm{mg} / \mathrm{dL})$ increase in fasting blood glucose was 1.14 (95\% confidence interval 1.06 to $1.22 ; P<0.001)$ without significant heterogeneity. Sensitivity analysis excluding blood glucose categories in the range of diabetes showed similar results (pooled rate ratio per $0.56 \mathrm{mmol} / \mathrm{L}$ increase in fasting blood glucose was $1.15,95 \%$ confidence interval 1.05 to $1.27 ; \mathrm{P}=0.003$ ), strengthening the association between prediabetes and pancreatic cancer.
\end{abstract}

Conclusions Every $0.56 \mathrm{mmol} / \mathrm{L}$ increase in fasting blood glucose is associated with a $14 \%$ increase in the rate of pancreatic cancer. As prediabetes can be improved or even reversed through lifestyle changes, early detection of prediabetes coupled with lifestyle changes could represent a viable strategy to curb the increasing incidence of pancreatic cancer.

\section{Introduction}

Pancreatic adenocarcinoma is the most lethal cancer, with a five year survival rate of less than $5 \%$. $^{1}$ The incidence and mortality rates of pancreatic cancer are increasing; it is the fifth and fourth leading cause of cancer deaths in the United Kingdom and the United States, respectively, and globally causes an estimated 227000 deaths a year. ${ }^{1-3}$ As about $85 \%$ of the tumors are already unresectable at diagnosis, ${ }^{1}$ prevention through modification of its risk factors is especially important. ${ }^{4}$ Epidemiological evidence supports type 2 diabetes as a risk factor for pancreatic cancer ${ }^{46}$ and chronic hyperinsulinaemia and hyperglycaemia associated with type 2 diabetes have been proposed as the underlying mechanism. Experimental evidence suggests that insulin promotes proliferation and reduces apoptosis in pancreatic cancer cells, both directly and indirectly through increased bioavailability of insulin-like growth factor $1 .{ }^{478}$ Hyperglycaemia can also enhance proliferation ${ }^{90}$ and invasion ability ${ }^{11}$ of pancreatic cancer cells. ${ }^{72}$ Hyperinsulinaemia and hyperglycaemia, however, are already present at the stage of prediabetes (blood glucose between normal and diabetes - that is, fasting blood glucose 5.6-6.9 mmol/L, post-load blood glucose 7.8-11.0 mmol/L, or haemoglobin $\mathrm{A}_{1 \mathrm{C}}$ 5.7-6.4\%), which precedes type 2 diabetes. ${ }^{13-15}$ Taken together, these observations 
suggest that prediabetes could also increase the risk of pancreatic cancer.

Whether prediabetes is a risk factor for pancreatic cancer has important implications for prevention. Prediabetes affects about $7.8 \%$ (344 million) of the world's adult population, ${ }^{16}$ but changes in lifestyle (weight loss, dietary modification, and physical activity) could improve and even reverse this..$^{13} 1518$ Previous epidemiological studies examining the association between blood glucose and pancreatic cancer, however, yielded inconsistent results, and the knowledge gap remains wide. The association between prediabetes and pancreatic cancer was significant in one study ${ }^{19}$ but non-significant in four others ${ }^{20-23}$; three studies had mixed results. ${ }^{24-26}$ No study assessed whether there is a threshold concentration of blood glucose that raises risk. Furthermore, those studies might have only modest statistical power as their categorisation of the continuous exposure (that is, glucose concentration) inevitably causes loss of information, ${ }^{27}{ }^{28}$ and the small number of patients with pancreatic cancer in many glucose categories could further reduce their power. Collectively, whether prediabetes indeed increases the risk of pancreatic cancer remains controversial, and the dose-response relation between blood glucose concentration and risk has not been investigated.

Dose-response meta-analysis is a potential solution to the above problems as it enables evaluation of both linear and non-linear dose-response relations and pools multiple studies to offer greater statistical power. ${ }^{28}{ }^{29}$ We therefore carried out a random effects dose-response meta-analysis to examine the relation between blood glucose concentrations and risk of pancreatic cancer.

\section{Methods}

\section{Search strategy and selection criteria}

This systematic review followed the guidelines in the MOOSE (Meta-analysis of Observational Studies in Epidemiology) statement. ${ }^{30}$ Two investigators (WCL and YKT) independently searched PubMed and Scopus and reviewed titles/abstracts in duplicate for studies that examined the association between blood glucose concentrations and pancreatic cancer from database inception to the end of November 2013 without language or date restrictions (see appendix 1 for the detailed study protocol with search strategies). We also manually searched bibliographies of included studies and related reviews for additional references. Studies that prospectively evaluated the association between blood glucose and pancreatic cancer were included for meta-analysis. As pancreatic cancer induces diabetes in about $40 \%$ of patients, ${ }^{31-33}$ we excluded retrospective and cross sectional studies to avoid reverse causality.

\section{Data extraction and assessment for study quality}

Two investigators (WCL and YKT) independently reviewed full manuscripts of eligible studies and extracted information into an electronic database, including author, publication year, country where the study was conducted, study design, sample size, duration of follow-up, methods of

measurement/categorisation of blood glucose concentrations and outcome ascertainment, number of cases, rate ratios and 95\% confidence intervals, and adjusted covariates. The same reviewers assessed study quality independently with the Newcastle-Ottawa scale. ${ }^{34}$ Disagreement was resolved by joint review of the manuscript to reach consensus.

\section{Data synthesis and analysis}

The outcome we analysed was the rate ratio of the incidence or mortality of pancreatic cancer; for pancreatic cancer incidence almost equals mortality. ${ }^{1}$ Random effects models were used for all meta-analyses to account for heterogeneity among studies. If only separate rate ratios for men and women were available in the original report, we pooled sex specific rate ratios using fixed effect models for subsequent meta-analysis when feasible. We used fasting blood glucose concentration as the exposure because it is the most reliable and convenient test for diagnosis of type 2 diabetes ${ }^{13}$ and was reported by most of the included studies. For studies that used haemoglobin $\mathrm{A}_{1 \mathrm{C}}$ or post-load blood glucose concentration after an oral glucose tolerance test as the exposure, we converted these data by using the following method: the cut off fasting blood glucose for prediabetes (5.6 $\mathrm{mmol} / \mathrm{L})$ and diabetes $(7.0 \mathrm{mmol} / \mathrm{L})$ were assumed to be equivalent to the cut offs of haemoglobin $\mathrm{A}_{1 \mathrm{c}}(5.7 \%$ and $6.5 \%)$ and post-load blood glucose $(7.8 \mathrm{mmol} / \mathrm{L}$ and $11.1 \mathrm{mmol} / \mathrm{L})$, respectively. ${ }^{135}$ This approach has been shown to have acceptable accuracy. ${ }^{35}$ For each of the included studies, we assigned the reported median or mean blood glucose concentration of each category as the category blood glucose concentration. When a study reported only the range of blood glucose for a category, we used the average value of the lower and upper bounds of that category. When the highest category was open ended, its category blood glucose concentration was calculated as the lower bound plus 1.5 times the width of the neighboring category. When the lowest category was open ended, its category blood glucose concentration was calculated as the average of the upper bound and 3.9 because the lower limit of fasting blood glucose is normally around $3.9 \mathrm{mmol} / \mathrm{L}{ }^{36}$

We first summarised the rate ratios for the highest versus the lowest category of fasting blood glucose in included studies using the random effects meta-analysis proposed by

DerSimonian and Laird (high $v$ low meta-analysis). ${ }^{37}$ Potential small study bias was evaluated by funnel plots and by Egger's test and Begg's test. ${ }^{38}$ Heterogeneity was evaluated by $\mathrm{I}^{2}$ and Cochran's Q. ${ }^{39}$ For dose response meta-analysis, we first estimated the study specific linear trends between exposure and outcome using the method described by Greenland and Longnecker, which accounts for correlation of the rate ratios within each study to avoid potential bias. ${ }^{28}{ }^{40}$ The estimated linear trends were then pooled with random-effects meta-analysis. ${ }^{37} \mathrm{Next}$, we explored potential non-linear dose-response relation in each study by using restricted cubic splines with three knots in the dose-response regression model, ${ }^{28} 29$ and results from each study were then pooled together with random effects multivariate meta-analysis. ${ }^{41}{ }^{42}$ The linear and non-linear models were compared with likelihood ratio tests. ${ }^{29} \mathrm{We}$ also examined sex specific effects by conducting separate meta-analyses for men and women.

For sensitivity analysis, we first repeated the analysis after excluding rate ratios that had an assigned fasting blood glucose concentration over $7.0 \mathrm{mmol} / \mathrm{L}$, the cut off for diagnosing diabetes, to assess whether the observed trend was mainly attributable to an increased rate of pancreatic cancer associated with type 2 diabetes and to exclude reverse causality from diabetes induced by pancreatic cancer. Secondly, we repeated the analysis after excluding studies that were incorporated using estimated fasting blood glucose concentrations or those that measured fasting blood glucose with variable fasting time among participants. Lastly, we conducted sensitivity analysis to examine whether using minimally adjusted rate ratios from included studies or different methods to assign blood glucose concentrations for open ended categories (the upper bound minus 
a half or the whole width of the neighboring category for the lowest category, and the lower bound plus the width or twice the width of the neighboring category for the highest category) would influence our results. The significance level was set at $5 \%$ throughout this study. The statistical analyses were performed with Stata version 12 (StataCorp, TX).

\section{Results}

We identified 2769 articles for review of title and abstract (fig $1 \Downarrow)$. After the initial screening, full text of potentially eligible articles was retrieved for detailed assessment. Nine eligible studies were included for meta-analysis, with a total of 2408 patients with pancreatic cancer. Table 1 summarises included studies, and table 2 shows rate ratios for various glucose concentrations $\Downarrow \Downarrow$. All included studies have been published as full manuscripts and are of high quality (see fig A, appendix 2).

Five studies used fasting blood glucose as the exposure. ${ }^{19} 20232526$ Among them, fasting time was variable in one study, ${ }^{26}$ with 58.0 $\%$ of the participants fasted for more than 4 hours. Fasting blood glucose was derived from haemoglobin $A_{1 c}$ in two studies ${ }^{24} 43$ and from post-load blood glucose concentration in two studies $^{21}{ }^{22}$. We calculated the number of cases of pancreatic cancer in each glucose category using the number of study population and cumulative incidence in one study ${ }^{25}$. Seven studies reported hazard ratios for pancreatic cancer. ${ }^{19-23}{ }^{25}{ }^{26}$ Odds ratios were reported in two nested case control studies, ${ }^{24}{ }^{43}$ which used incidence density sampling for selecting control subjects; therefore, the obtained odds ratios meant rate ratios. ${ }^{44}$ Three studies exclusively reported sex specific rate ratios. ${ }^{23} 25$. In two of them we carried out pooling of sex specific rate ratios for subsequent meta-analysis, ${ }^{23}{ }^{25}$ but this was not feasible in one study ${ }^{26}$ because the categorisation of blood glucose was different between sexes. We used sex specific rate ratios to incorporate that study.

For high versus low meta-analysis, we included all nine studies. No significant small study bias was found (Begg's test $\mathrm{P}=0.59$, Egger's test $\mathrm{P}=0.71$; fig $\mathrm{B}$ in appendix 2). The pooled rate ratio of pancreatic cancer for the highest versus the lowest category of fasting blood glucose was 1.83 (95\% confidence interval 1.50 to 2.24$)$, with significant heterogeneity $\left(\mathrm{I}^{2}=52.4 \%, \mathrm{P}=0.026\right)$ (fig $2 \Downarrow$ ).

For dose-response meta-analysis, we excluded one study that divided glucose concentration into only two categories ${ }^{23}$ because at least three exposure categories are needed to estimate the study specific trend. ${ }^{28}$ Figure $3 \Downarrow$ summarises the estimated study specific linear trends of the relation between fasting blood glucose and rate ratio and the pooled estimate from random effects meta-analysis. There was a positive dose-response relation between fasting blood glucose concentration and the rate of pancreatic cancer (pooled rate ratio was 1.14 (95\% confidence interval 1.06 to 1.24$)$ per $0.56 \mathrm{mmol} / \mathrm{L}(10 \mathrm{mg} / \mathrm{dL})$ increase in fasting blood glucose concentration), without significant heterogeneity across studies $\left(\mathrm{P}=0.21, \mathrm{I}^{2}=26.8 \%\right)$. No individual study had excessive influence on the summary estimate (see fig $\mathrm{C}$ in appendix 2).

Figure 4 shows the results of non-linear dose-response meta-analysis $\Downarrow$. There was a linear relation between fasting blood glucose and the rate of pancreatic cancer across both prediabetes and diabetes, whereas no significant non-linear association was noted $(\mathrm{P}=0.52$ for the comparison between linear and non-linear models). The pooled rate ratio of pancreatic cancer per $0.56 \mathrm{mmol} / \mathrm{L}$ increase in fasting blood glucose was 1.14 (95\% confidence interval 1.06 to $1.22, \mathrm{P}<0.001$ ) across the range between $4.1 \mathrm{mmol} / \mathrm{L}$ and $10.6 \mathrm{mmol} / \mathrm{L}$, without significant heterogeneity. For sex specific analyses, five studies reported rate ratios for men 2021222526 and three studies reported rate ratios for women. ${ }^{2125} 26$ The results of sex specific analyses (see appendix 2 for meta-analyses of high $v$ low (fig D), linear trend (fig E), and non-linear dose-response in men/women (figs $\mathrm{F}$ and $\mathrm{G})$ ) were in line with those of analyses combining both sexes, showing a linear relation between fasting blood glucose and the rate of pancreatic cancer. The pooled rate ratio of pancreatic cancer per $0.56 \mathrm{mmol} / \mathrm{L}$ increase in fasting blood glucose was 1.05 (0.99 to $1.12 ; \mathrm{P}=0.13)$ in men and 1.17 (1.07 to $1.29 ; \mathrm{P}=0.001$ ) in women.

Sensitivity analyses showed similar results. When we excluded categories with an assigned fasting blood glucose concentration over $7.0 \mathrm{mmol} / \mathrm{L}$, the pooled rate ratio per $0.56 \mathrm{mmol} / \mathrm{L}$ increase in fasting blood glucose was 1.15 (95\% confidence interval 1.05 to $1.27 ; \mathrm{P}=0.003$ ) (fig $5 \Downarrow$ ). After we excluded two studies that measured post-load blood glucose $\mathrm{e}^{21}$ and two studies that measured haemoglobin $\mathrm{A}_{1 \mathrm{C}},{ }^{24}{ }^{43}$ the pooled rate ratio per 0.56 $\mathrm{mmol} / \mathrm{L}$ increase in fasting blood glucose was 1.11 (1.02 to 1.20; $\mathrm{P}=0.021$ ) (see fig $\mathrm{H}$, appendix 2). Exclusion of the study that had variable fasting time ${ }^{26}$ or use of minimally adjusted rate ratios for meta-analysis had little influence on the results (pooled rate ratios per $0.56 \mathrm{mmol} / \mathrm{L}$ increase in fasting blood glucose were 1.14 (1.07 to $1.21 ; \mathrm{P}<0.001)$ and 1.13 (1.07 to 1.21; $\mathrm{P}<0.001)$, respectively). Use of different methods to assign blood glucose concentrations for open ended categories also had negligible impacts on the results (see table A in appendix 2).

\section{Discussion}

There is a linear dose-response relation between fasting blood glucose concentration and the rate of pancreatic cancer across prediabetes and diabetes, with every $0.56 \mathrm{mmol} / \mathrm{L}$ increase in fasting blood glucose associated with a $14 \%$ increase in the rate of pancreatic cancer. We used meta-analysis to evaluate the association between prediabetes and pancreatic cancer and to investigate the dose-response relations between blood glucose concentrations and risk of pancreatic cancer.

\section{Comparisons with individual studies}

This meta-analysis provides novel insights into the association between abnormal glucose metabolism and pancreatic cancer. In previous research, the association between prediabetes and pancreatic cancer was significant in only one study ${ }^{19}$ but non-significant in four, ${ }^{20-23}$ mixed in three, ${ }^{24-26}$ and unclear in one study ${ }^{42}$. By pooling all those studies, this meta-analysis shows that the rate of pancreatic cancer increases linearly with worsening hyperglycaemia throughout prediabetes and diabetes. Several reasons might explain the seemingly conflicting results of those individual studies. The distribution and categorisation of glucose concentration varied among studies, thus the ranges of glucose concentrations compared to derive the rate ratios differed among studies and the rate ratios could not be directly compared. Secondly, many categories of glucose concentration in the range of prediabetes contained only a small number of patients with pancreatic cancer, yielding rate ratios with wide $95 \%$ confidence intervals (table $2 \Downarrow$ ). By contrast, our meta-analysis assessed the change in the rate of pancreatic cancer per unit increase in fasting blood glucose in each study, and pooling of multiple studies provided greater statistical power and more precise estimates. It is worth noting that while the rate ratio for the highest versus the lowest blood glucose categories was heterogeneous among included studies, the trend of rate ratio in relation to blood glucose was actually similar across 
those studies without significant heterogeneity. Our results support that fasting hyperglycaemia is a dose-dependent risk factor for pancreatic cancer.

\section{Possible explanations and implications}

The dose-response relation between blood glucose concentration and risk of pancreatic cancer might be attributed to the fact that pancreatic cancer cells depend heavily on glucose for growth. While the normal pancreas metabolises glucose through oxidative phosphorylation, pancreatic cancer cells preferentially metabolise glucose through aerobic glycolysis, which generates less energy but more metabolites required for biosynthetic functions to sustain cell proliferation and thus confers a survival advantage (Warburg effect). ${ }^{12} 334546$ To compensate for the inefficient energy production and meet the growing need for energy and biosynthesis, pancreatic cancer cells have a high requirement for glucose ("glucose addiction") and exhibit increased glucose uptake. ${ }^{75} 47$ Therefore, hyperglycaemia might increase the risk of pancreatic cancer by providing more glucose to fuel tumor growth.

Our results support that prediabetes/type 2 diabetes is a modifiable risk factor for pancreatic cancer in addition to smoking and obesity. ${ }^{4}$ Although we cannot completely exclude the possibility of residual confounding by smoking and obesity, the potential extent of confounding is likely small. In all but one study ${ }^{25}$ included for dose-response meta-analysis, the rate ratios had been adjusted for smoking and body mass index (BMI). While Jee and colleagues presented rate ratios that adjusted for smoking but not BMI, they pointed out that their participants were far leaner than those in studies from Western populations and further adjustment for BMI had little influence on the rate ratios. ${ }^{25}$

The discovery that risk of pancreatic cancer progressively increases with worsening hyperglycaemia has important implications. Our findings imply that the increasing incidence of pancreatic cancer ${ }^{2}$ might be attributed to the rapid increase in prediabetes/diabetes, a global epidemic affecting 14.2\% (629 million) of the world's adult population. ${ }^{16}{ }^{48}$ Furthermore, prediabetes could provide an important opportunity for prevention of pancreatic cancer, the most effective strategy to reduce related mortality ${ }^{4}$ given that pancreatic cancer evades early detection and responds poorly to treatment. ${ }^{1}$ Prediabetes precedes overt type 2 diabetes and can be improved or even reversed through changes in lifestyle. ${ }^{13}{ }^{15}{ }^{17}$ Two previous randomised trials have shown that counselling on weight loss, diet, and physical activity for individuals with prediabetes could decrease fasting blood glucose concentrations and reduce the risk of progression to type 2 diabetes by about $60 \% .{ }^{17}{ }^{18}$ Efforts toward early detection of prediabetes in conjunction with implementation of lifestyle changes to improve glucose metabolism could represent a viable strategy to curb the increasing incidence of pancreatic cancer and should be further evaluated.

\section{Strengths and limitations of this study}

Our study deals with the limitations of existing research and has several strengths. Previous studies assumed a linear increase in risk with rising blood glucose from normal to diabetes, without assessing whether a threshold for blood glucose concentration existed and if the observed trend resulted mainly from increased risk in the range of diabetes. ${ }^{2025}{ }^{26}$ Furthermore, pancreatic cancer induces diabetes in about $40 \%$ of patients, ${ }^{31} 32$ raising concerns that the association between diabetes and pancreatic cancer could be partly because of reverse causality.
To resolve these issues, we examined both linear and non-linear dose-response relations between fasting blood glucose and risk of pancreatic cancer to assess whether there is a threshold for blood glucose concentration, rather than assuming linearity without justification. To confirm the association between prediabetes and pancreatic cancer and to exclude possible reverse causality from diabetes induced by pancreatic cancer, we conducted pre-specified sensitivity analysis excluding glucose categories in the diabetes range. We also accounted for correlation among the rate ratios based on a common reference group in each study to avoid underestimating the variance of the study specific trend, which could yield misleading results. ${ }^{28} 40$ Our results are robust and provide firm support that prediabetes is also associated with increased risk of pancreatic cancer.

Our study also has some limitations. Firstly, only a few studies reported sex specific rate ratios; therefore, results from sex specific meta-analyses were based on a small amount of evidence and should be interpreted with caution. Secondly, information on the use of antidiabetic drugs was not available in the included studies. During follow-up, participants with diabetes might receive antidiabetic drugs that could cause changes in blood glucose concentrations from baseline. Participants without diabetes, however, were unlikely to receive antidiabetic drugs, and this factor should have little influence on our results in the blood glucose range below diabetes. Thirdly, we excluded one study that reported rate ratios of pancreatic cancer for diabetes and prediabetes because it did not provide the distribution of blood glucose concentration and the number of cases in each category, ${ }^{49}$ and thus we could not determine the blood glucose concentrations associated with the rate ratios with precision and estimate the correlation among the rate ratios. When we included this study in the analysis with imputed blood glucose concentrations, and assumed no correlation among the rate ratios, there was little influence on our results. We also excluded one study that did not categorise blood glucose but reported the linear trend between fasting blood glucose and rate ratio of pancreatic cancer. ${ }^{50}$ Although this study could be incorporated into the linear dose-response meta-analysis, we decided to completely exclude this study because blood glucose was measured after diagnosis of pancreatic cancer in 19 of its 48 patients, raising concerns of reverse causality from diabetes induced by pancreatic cancer. Lastly, our meta-analysis was conducted with summary statistics rather than individual data. Access to and examination of data from individual participants could allow more precise delineation of the dose-response relation and further control of potential residual confounding.

\section{Conclusions}

Our dose-response meta-analysis shows that every $0.56 \mathrm{mmol} / \mathrm{L}$ increase in fasting blood glucose is associated with a $14 \%$ increase in the rate of pancreatic cancer. Prediabetes is also a risk factor for pancreatic cancer and provides an opportunity for prevention of pancreatic cancer.

Contributors: All authors had full access to all of the data in the study and take responsibility for the integrity of the data and the accuracy of the data analysis. W-CL, Y-KT, and K-LC contributed to study concept and design, data analysis and interpretation, and writing of the report. M-SW, J-TL, and H-PW contributed to data interpretation and provided intellectual enrichment to the report. All authors met the ICMJE criteria for authorship. All authors agree with the manuscript results and conclusions. Y-KT and K-LC are guarantors.

Funding: The study was supported partly by grants from the National Science Council in Taiwan (grants NSC 101-2314-B-002-197-MY2 and 


\section{What is already known on this topic}

Type 2 diabetes is an established risk factor for pancreatic adenocarcinoma, the most lethal cancer

Prediabetes precedes type 2 diabetes and can be improved or reversed through lifestyle changes, suggesting that prediabetes might be a risk factor for pancreatic cancer and an opportunity for prevention

Whether prediabetes increases the risk of pancreatic cancer remains unclear; previous studies yielded inconsistent results, and no systematic review has assessed the dose-response relation between blood glucose and risk

\section{What this study adds}

The rate of pancreatic cancer increases linearly by $14 \%$ with every $0.56 \mathrm{mmol} / \mathrm{L}(10 \mathrm{mg} / \mathrm{dL})$ increase in fasting blood glucose across both prediabetes and diabetes

Efforts toward early detection of prediabetes and lifestyle changes to improve glucose metabolism could represent a viable strategy to curb the increasing incidence of pancreatic cancer

NSC 101-2325-B-002-027). The sponsors had no role in the study design; collection, analysis, and interpretation of data; writing of the report; and decision to submit the article for publication.

Competing interests: All authors have completed the ICMJE uniform disclosure form at www.icmje.org/coi_disclosure.pdf (available on request from the corresponding author) and declare: no support from any organisation for the submitted work; no financial relationships with any organisations that might have an interest in the submitted work in the previous three years; no other relationships or activities that could appear to have influenced the submitted work.

Ethical approval: Not required.

Data sharing: No additional data available.

Transparency: The lead author (the manuscript's guarantor) affirms that the manuscript is an honest, accurate, and transparent account of the study being reported; that no important aspects of the study have been omitted; and that any discrepancies from the study as planned (and, if relevant, registered) have been explained.

1 Siegel R, Ma J, Zou Z, Jemal A. Cancer statistics, 2014. CA Cancer J Clin 2014;64:9-29. 2 Cancer Research UK. Cancer mortality for common cancers. www.cancerresearchuk.org/ cancer-info/cancerstats/mortality/cancerdeaths/.

3 Raimondi S, Maisonneuve P, Lowenfels AB. Epidemiology of pancreatic cancer: an overview. Nat Rev Gastroenterol Hepatol 2009;6:699-708.

$4 \quad$ Li D. Diabetes and pancreatic cancer. Mol Carcinog 2012;51:64-74.

5 Andersen DK. Diabetes and cancer: placing the association in perspective. Curr Opin Endocrinol Diabetes Obes 2013:20:81-6.

6 Huxley R, Ansary-Moghaddam A, Berrington de Gonzalez A, Barzi F, Woodward M. Type-II diabetes and pancreatic cancer: a meta-analysis of 36 studies. Br J Cancer 2005;92:2076-83

7 Giovannucci E, Harlan DM, Archer MC, Bergenstal RM, Gapstur SM, Habel LA, et al. Diabetes and cancer: a consensus report. Diabetes Care 2010;33:1674-85.

8 Sandhu MS, Dunger DB, Giovannucci EL. Insulin, insulin-like growth factor-I (IGF-I), IGF binding proteins, their biologic interactions, and colorectal cancer. J Natl Cancer Inst 2002:94:972-80

9 Butler AE, Galasso R, Matveyenko A, Rizza RA, Dry S, Butler PC. Pancreatic duct replication is increased with obesity and type 2 diabetes in humans. Diabetologia 2010;53:21-6.

$10 \mathrm{Han} \mathrm{L,} \mathrm{Ma} \mathrm{Q,} \mathrm{Li} \mathrm{J,} \mathrm{Liu} \mathrm{H,} \mathrm{Li} \mathrm{W,} \mathrm{Ma} \mathrm{G,} \mathrm{et} \mathrm{al.} \mathrm{High} \mathrm{glucose} \mathrm{promotes} \mathrm{pancreatic} \mathrm{cancer} \mathrm{cell}$ proliferation via the induction of EGF expression and transactivation of EGFR. PLoS One 2011;6:8

11 Li J, Ma Q, Liu H, Guo K, Li F, Li W, et al. Relationship between neural alteration and perineural invasion in pancreatic cancer patients with hyperglycemia. PLoS One 2011;6:0017385

12 Vander Heiden MG, Cantley LC, Thompson CB. Understanding the Warburg effect: the metabolic requirements of cell proliferation. Science 2009;324:1029-33.

13 Powers AC. Diabetes Mellitus. In: Longo DL FA, Kasper DL, Hauser SL, Jameson JL, Loscalzo J, editors. Harrison's principles of internal medicine. 18th ed. McGraw-Hill, 2012.

14 Centers for Disease Control and Prevention. National diabetes fact sheet: national estimates and general information on diabetes and prediabetes in the United States, 2011. www.cdc.gov/diabetes/pubs/factsheets.htm.

15 Nathan DM, Davidson MB, DeFronzo RA, Heine RJ, Henry RR, Pratley R, et al. Impaired fasting glucose and impaired glucose tolerance: implications for care. Diabetes Care 2007;30:753-9

16 Sicree R, Shaw J, Zimmet P. The global burden. Diabetes and impaired glucose tolerance. IDF Diabetes Atlas. 4th ed. International Diabetes Federation, 2009:1-105.

17 Tuomilehto J, Lindstrom J, Eriksson JG, Valle TT, Hamalainen H, llanne-Parikka P, et al . Prevention of type 2 diabetes mellitus by changes in lifestyle among subjects with impaired glucose tolerance. N Engl J Med 2001;344:1343-50.

18 Diabetes Prevention Program Research Group. Reduction in the incidence of type 2 diabetes with lifestyle intervention or metformin. N Engl J Med 2002;346:393-403.

19 Ansary-Moghaddam A, Huxley R, Barzi F, Lawes C, Ohkubo T, Fang X, et al. The effect of modifiable risk factors on pancreatic cancer mortality in populations of the Asia-Pacific region. Cancer Epidemiol Biomarkers Prev 2006;15:2435-40.

20 Stolzenberg-Solomon RZ, Graubard BI, Chari S, Limburg P, Taylor PR, Virtamo J, et al. Insulin, glucose, insulin resistance, and pancreatic cancer in male smokers. JAMA 2005;294:2872-8.
21 Gapstur SM, Gann PH, Lowe W, Liu K, Colangelo L, Dyer A. Abnormal glucose metabolism and pancreatic cancer mortality. JAMA 2000;283:2552-8.

22 Batty GD, Shipley MJ, Marmot M, Smith GD. Diabetes status and post-load plasma glucose concentration in relation to site-specific cancer mortality: findings from the original Whitehall study. Cancer Causes Control 2004:15:873-81.

23 Inoue M, Noda M, Kurahashi N, Iwasaki M, Sasazuki S, Iso H, et al. Impact of metabolic factors on subsequent cancer risk: results from a large-scale population-based cohort study in Japan. Eur J Cancer Prev 2009;18:240-7.

24 Grote VA, Rohrmann S, Nieters A, Dossus L, Tjonneland A, Halkjaer J, et al. Diabetes mellitus, glycated haemoglobin and C-peptide levels in relation to pancreatic cancer risk: a study within the European Prospective Investigation into Cancer and Nutrition (EPIC) cohort. Diabetologia ;54:3037-46.

25 Jee SH, Ohrr H, Sull JW, Yun JE, Ji M, Samet JM. Fasting serum glucose level and cancer risk in Korean men and women. JAMA 2005;293:194-202.

26 Johansen D, Stocks T, Jonsson H, Lindkvist B, Bjorge T, Concin H, et al. Metabolic factors and the risk of pancreatic cancer: a prospective analysis of almost 580,000 men and women in the Metabolic Syndrome and Cancer Project. Cancer Epidemiol Biomarkers Prev 2010:19:2307-17.

27 Greenland S. Avoiding power loss associated with categorization and ordinal scores in dose-response and trend analysis. Epidemiology 1995;6:450-4.

28 Orsini N, Li R, Wolk A, Khudyakov P, Spiegelman D. Meta-analysis for linear and nonlinear dose-response relations: examples, an evaluation of approximations, and software. $A m$ J Epidemiol 2012;175:66-73.

29 Desquilbet L, Mariotti F. Dose-response analyses using restricted cubic spline functions in public health research. Stat Med 2010;29:1037-57.

30 Stroup DF, Berlin JA, Morton SC, Olkin I, Williamson GD, Rennie D, et al. Meta-analysis of observational studies in epidemiology: a proposal for reporting. Meta-analysis Of Observational Studies in Epidemiology (MOOSE) group. JAMA 2000;283:2008-12.

31 Aggarwal G, Kamada P, Chari ST. Prevalence of diabetes mellitus in pancreatic cancer compared to common cancers. Pancreas 2012;20:20.

32 Pannala R, Leirness JB, Bamlet WR, Basu A, Petersen GM, Chari ST. Prevalence and clinical profile of pancreatic cancer-associated diabetes mellitus. Gastroenterology 2008;134:981-7.

33 Sah RP, Nagpal SJ, Mukhopadhyay D, Chari ST. New insights into pancreatic cancer-induced paraneoplastic diabetes. Nat Rev Gastroenterol Hepatol 2013;10:423-33.

4 Wells GA, Shea B, O'Connell D, Peterson J, Welch V, Losos M, et al. The Newcastle-Ottawa Scale (NOS) for assessing the quality of nonrandomised studies in meta-analyses. www.medicine.mcgill.ca/rtamblyn/Readings $\% 5$ CThe $\% 20$ Newcastle $\% 20$ $\% 20$ Scale\%20for\%20assessing\%20the\%20quality\%20of\%20nonrandomised\%20studies\% 20in\%20meta-analyses.pdf.

35 Kumaravel B, Bachmann MO, Murray N, Dhatariya K, Fenech M, John WG, et al. Use of haemoglobin A1c to detect impaired fasting glucose or type 2 diabetes in a United Kingdom community based population. Diabetes Res Clin Pract 2012;96:211-6.

36 Cryer PE, David SN. Hypoglycemia. In: Longo DL FA, Kasper DL, Hauser SL, Jameson $\mathrm{JL}$, Loscalzo J, eds. Harrison's principles of internal medicine. McGraw-Hill, 2012.

37 DerSimonian R, Laird N. Meta-analysis in clinical trials. Control Clin Trials 1986;7:177-88.

38 Egger M, Davey Smith G, Schneider M, Minder C. Bias in meta-analysis detected by a simple, graphical test. BMJ 1997;315:629-34.

39 Higgins JP, Thompson SG, Deeks JJ, Altman DG. Measuring inconsistency in meta-analyses. BMJ 2003;327:557-60.

40 Greenland S, Longnecker MP. Methods for trend estimation from summarized dose-response data, with applications to meta-analysis. Am J Epidemiol 1992;135:1301-9.

41 White IR. Multivariate random-effects meta-analysis. Stata J 2009:9:40-56.

42 Orsini N, Bellocco R, Greenland S. Generalized least squares for trend estimation of summarized dose-response data. Stata J 2006;6:40-57.

43 Wolpin BM, Bao Y, Qian ZR, Wu C, Kraft P, Ogino S, et al. Hyperglycemia, insulin resistance, impaired pancreatic $\beta$-cell function, and risk of pancreatic cancer. J Natl Cance Inst 2013;105:1027-35.

44 Pearce N. What does the odds ratio estimate in a case-control study? Int J Epidemiol 1993;22:1189-92.

45 Regel I, Kong B, Raulefs S, Erkan M, Michalski CW, Hartel M, et al. Energy metabolism and proliferation in pancreatic carcinogenesis. Langenbecks Arch Surg 2012;397:507-12.

46 Warburg O. On respiratory impairment in cancer cells. Science 1956;124:269-70.

47 Chaika NV, Yu F, Purohit V, Mehla K, Lazenby AJ, DiMaio D, et al. Differential expression of metabolic genes in tumor and stromal components of primary and metastatic loci in pancreatic adenocarcinoma. PLOS One 2012;7:7.

48 Danaei G, Finucane MM, Lu Y, Singh GM, Cowan MJ, Paciorek CJ, et al. National, regional, and global trends in fasting plasma glucose and diabetes prevalence since 1980 systematic analysis of health examination surveys and epidemiological studies with 370 country-years and 2.7 million participants. Lancet 2011;378:31-40.

49 Balkau B, Barrett-Connor E, Eschwege E, Richard JL, Claude JR, Ducimetiere P. Diabetes and pancreatic carcinoma. Diabete Metab 1993;19:458-62.

50 Hiatt RA, Klatsky AL, Armstrong MA. Pancreatic cancer, blood glucose and beverage consumption. Int $J$ Cancer 1988;41:794-7.

Accepted: 30 October 2014 
Cite this as: BMJ 2015;350:g7371

This is an Open Access article distributed in accordance with the Creative Commons Attribution Non Commercial (CC BY-NC 4.0) license, which permits others to distribute, remix, adapt, build upon this work non-commercially, and license their derivative works on different terms, provided the original work is properly cited and the use is non-commercial. See: http://creativecommons.org/licenses/by-nc/4.0/. 


\section{Tables}

Table 1/ Summary of prospective studies included in systematic review and dose-response meta-analysis on blood glucose concentration and rate of pancreatic cancer

\begin{tabular}{|c|c|c|c|c|c|c|c|}
\hline Study & Region & Design & Mean age (years) & Women (\%) & Baseline & $\begin{array}{c}\text { Duration of } \\
\text { follow-up (year) }\end{array}$ & Adjusted variables \\
\hline Gapstur, $2000^{21}$ & North America & Cohort & 39.9 & 42.6 & 1963-73 & 25 (mean) & Age, race, smoking, BMI \\
\hline Batty, $2004^{22}$ & Europe & Cohort & 51.5 & 0 & $1967-70$ & 25 & $\begin{array}{l}\text { Age, smoking, BMI, } \\
\text { physical activity, etc }\end{array}$ \\
\hline $\begin{array}{l}\text { Stolzenberg-Solomon, } \\
2005^{20}\end{array}$ & Europe & Case cohort & 57.2 & 0 & $1985-88$ & 13.8 (median) & Age, smoking, BMI \\
\hline Jee, $2005^{25}$ & Asia & Cohort & 46.9 & 36.1 & 1992-95 & 10 & $\begin{array}{l}\text { Age, age }{ }^{2} \text {, smoking, } \\
\text { alcohol }\end{array}$ \\
\hline $\begin{array}{l}\text { Ansary-Moghaddam, } \\
2006^{\star 19}\end{array}$ & $\begin{array}{l}\text { Asia, } \\
\text { Australia/New } \\
\text { Zealand }\end{array}$ & Cohort & 46.3 & 35.3 & $1961-99$ & 6.8 (median) & $\begin{array}{l}\text { Age, sex, study, } \\
\text { smoking, BMI }\end{array}$ \\
\hline Inoue, $2009^{23}$ & Asia & Cohort & 55.8 & 65.6 & $1990-94$ & 10.2 (mean) & $\begin{array}{l}\text { Age, area, smoking, } \\
\text { alcohol, cholesterol }\end{array}$ \\
\hline \multirow[t]{2}{*}{ Johansen, $2010 \dagger^{26}$} & \multirow[t]{2}{*}{ Europe } & \multirow[t]{2}{*}{ Cohort } & Male 43.9 & - & $1972-2005$ & 12.8 (mean) & \multirow[t]{2}{*}{ Smoking, BMI, age } \\
\hline & & & Female 44.1 & 49.9 & $1972-2005$ & 11.3 (mean) & \\
\hline Grote, $2011^{24}$ & Europe & $\begin{array}{l}\text { Nested } \\
\text { case-control }\end{array}$ & $\begin{array}{l}58 \text { (cases), } 58 \\
\text { (control) }\end{array}$ & $\begin{array}{l}51.7 \text { (cases), } \\
51.7 \text { (control) }\end{array}$ & $1992-2000$ & 5.3 (mean) & $\begin{array}{l}\text { Smoking, BMI, matched } \\
\text { for date, sex, age, food, } \\
\text { drink, centre }\end{array}$ \\
\hline Wolpin, $2013 \ddagger^{43}$ & North America & $\begin{array}{l}\text { Nested } \\
\text { case-control }\end{array}$ & $\begin{array}{c}63.1 \text { (cases), } 62.5 \\
\text { (control) }\end{array}$ & $\begin{array}{l}71.5 \text { (cases), } \\
70.7 \text { (control) }\end{array}$ & $1976-98$ & 12.2-25.3 (median) & $\begin{array}{l}\text { Cohort, smoking, BMI, } \\
\text { fasting time, age, race, } \\
\text { sex }\end{array}$ \\
\hline
\end{tabular}

BMl=body mass index.

*Pooled analysis of 30 cohorts. Australia: Busselton, Canberra-Queanbeyan, Long. Study of Aging, Melbourne, National Heart Foundation, Newcastle, Perth, WA AAA Screenees; New Zealand: Fletcher Challenge; China: Anzhen, East Beijing, Guangzhou Occupational, Seven Cities Cohorts, Six Cohorts, Tianjin, Xi'an; Hong Kong: Hong Kong; Japan: Aita town, Akabane, Civil Service Workers, Hisayama, Konan, Ohasama, Saitama, Shibata, Shigaraki Town, Shirakawa; Singapore: Singapore Heart; South Korea: KMIC; Taiwan: CVDFACTS.

†Pooled analysis of seven cohorts. Austria: Vorarlberg Health Monitoring and Prevention Program; Norway: Oslo study I cohort, Norwegian Counties Study, Cohort of Norway, Age 40-programme; Sweden: Västerbotten Intervention Project, Malmö Preventive Project.

‡Pooled analysis of five cohorts in US: Health Professionals Follow-up Study, Nurses' Health Study, Physicians' Health Study, Women’s Health Initiative-Observational Study, Women's Health Study. 
Table 2| Rate ratios for pancreatic cancer in studies included in systematic review and dose-response meta-analysis on blood glucose concentration and rate of pancreatic cancer

Fasting blood glucose (mmol/L) No of cases/total or person years (PY) Rate ratio $(95 \% \mathrm{Cl})$

Gapstur, 2000 ${ }^{21}$

\begin{tabular}{|c|c|c|}
\hline$<5.1^{*}$ & 30/379 $686 \mathrm{PY}$ & 1 \\
\hline $5.1-5.9^{*}$ & 55/265 $062 \mathrm{PY}$ & 1.65 (1.05 to 2.60$)$ \\
\hline $6.0-6.9^{*}$ & $31 / 116475 \mathrm{PY}$ & 1.60 (0.95 to 2.70$)$ \\
\hline$\geq 7.0^{*}$ & 23/52 $731 \mathrm{PY}$ & 2.15 (1.22 to 3.80$)$ \\
\hline \multicolumn{3}{|c|}{ Batty, $2004^{22}$} \\
\hline \multicolumn{3}{|l|}{ Men: } \\
\hline$<5.6^{*}$ & $102 / 16843$ & 1 \\
\hline $5.6-6.9^{*}$ & $8 / 975$ & 1.35 (0.66 to 2.80$)$ \\
\hline$\geq 7.0^{*}$ & $4 / 188$ & $3.99(1.44$ to 11.0$)$ \\
\hline \multicolumn{3}{|c|}{ Stolzenberg-Solomon, $2005^{20}$} \\
\hline \multicolumn{3}{|l|}{ Men: } \\
\hline$<5.2$ & $34 / 133$ & 1 \\
\hline $5.2-5.4$ & $37 / 137$ & 1.15 (0.66 to 2.02$)$ \\
\hline $5.5-5.9$ & $48 / 150$ & 1.49 (0.86 to 2.59$)$ \\
\hline$>5.9$ & $50 / 149$ & 1.69 (0.97 to 2.94$)$ \\
\hline \multicolumn{3}{|c|}{ Jee, $2005^{25}$} \\
\hline \multicolumn{3}{|l|}{ Men: } \\
\hline$<5.0$ & $59 / 429370 \dagger$ & 1 \\
\hline $5.0-6.0$ & 43/304 362† & $1.08(0.95$ to 1.24$)$ \\
\hline 6.1-6.9 & $10 / 58020 \dagger$ & 1.34 (1.09 to 1.64$)$ \\
\hline $7.0-7.7$ & $2 / 11459 \dagger$ & $1.37(0.94$ to 2.00$)$ \\
\hline$\geq 7.8$ & $8 / 26559+$ & 2.09 (1.70 to 2.58$)$ \\
\hline \multicolumn{3}{|l|}{ Women: } \\
\hline$<5.00$ & $20 / 270157 \dagger$ & 1 \\
\hline $5.0-6.0$ & $15 / 157940 \dagger$ & $1.27(1.03$ to 1.57$)$ \\
\hline $6.1-6.9$ & 3/22 578† & 1.39 (0.96 to 2.02$)$ \\
\hline $7.0-7.7$ & $1 / 5657 \dagger$ & 1.99 (1.13 to 3.49$)$ \\
\hline$\geq 7.8$ & $2 / 12283 \dagger$ & $1.67(1.09$ to 2.56$)$ \\
\hline \multicolumn{3}{|c|}{ Ansary-Moghaddam, 2006 $\ddagger^{19}$} \\
\hline$<5.2$ & $28 / 125855$ & 1 \\
\hline $5.2-5.8$ & $28 / 41118$ & $1.79(1.03$ to 3.10$)$ \\
\hline$>5.8$ & 29/27 041 & 2.08 (1.18 to 3.67$)$ \\
\hline \multicolumn{3}{|c|}{ Inoue, $2009^{23}$} \\
\hline \multicolumn{3}{|l|}{ Men: } \\
\hline$<5.6$ & 20/73 $285 \mathrm{PY}$ & 1 \\
\hline$>5.6$ & 4/21 687 PY & 0.74 (0.24 to 2.22$)$ \\
\hline \multicolumn{3}{|l|}{ Women: } \\
\hline$<5.6$ & 35/165 838 PY & 1 \\
\hline$>5.6$ & 6/22 683 PY & 1.00 (0.42 to 2.39$)$ \\
\hline \multicolumn{3}{|c|}{ Johansen, $2010 \S^{26}$} \\
\hline \multicolumn{3}{|c|}{ Mean (SD) men: } \\
\hline $4.2(0.5)$ & 102/772 727 PYף & 1 \\
\hline $4.8(0.3)$ & 81/743 119 PYף & 0.81 (0.60 to 1.08$)$ \\
\hline $5.1(0.3)$ & 121/751 553 PY & 1.14 (0.88 to 1.49$)$ \\
\hline $5.6(0.3)$ & 101/711 268 PYף & 1.01 (0.76 to 1.34$)$ \\
\hline $6.9(2.0)$ & 138/718 750 PYף & $1.24(0.95$ to 1.61$)$ \\
\hline
\end{tabular}




\section{Table 2 (continued)}

Fasting blood glucose (mmol/L) No of cases/total or person years (PY) Rate ratio (95\% Cl)

\begin{tabular}{|c|c|c|}
\hline $4.1(0.6)$ & 34/666 667 PYף & 1 \\
\hline $4.8(0.4)$ & 51/680 000 PYף & 1.36 (0.88 to 2.09$)$ \\
\hline $5.0(0.4)$ & 49/628 205 PYף & $1.32(0.85$ to 2.05$)$ \\
\hline $5.4(0.4)$ & 73/669 725 PYף & 1.79 (1.19 to 2.70$)$ \\
\hline $7.1(3.3)$ & 106/612 717 PYף & 2.39 (1.61 to 3.54$)$ \\
\hline \multicolumn{3}{|l|}{ Grote, $2011^{24}$} \\
\hline $4.3-5.3^{* *}$ & $72 / 173$ & 1 \\
\hline $5.4-5.8^{* *}$ & $131 / 282$ & 1.27 (0.84 to 1.93$)$ \\
\hline $5.9-6.1^{\star *}$ & $102 / 184$ & 1.77 (1.14 to 2.75$)$ \\
\hline $6.2-6.9^{* *}$ & $97 / 188$ & 1.46 (0.93 to 2.30$)$ \\
\hline $7.0-14.2^{\star *}$ & $54 / 85$ & 2.42 (1.33 to 4.39$)$ \\
\hline \multicolumn{3}{|c|}{ Wolpin, 2013 $t t^{43}$} \\
\hline Median $4.2^{\star *}$ & $61 / 246$ & 1 \\
\hline Median $4.5^{\star *}$ & $92 / 276$ & 1.59 (1.07 to 2.36$)$ \\
\hline Median $4.7^{* *}$ & $101 / 286$ & 1.82 (1.22 to 2.70$)$ \\
\hline Median $5.0^{* *}$ & $74 / 262$ & 1.36 (0.89 to 2.07$)$ \\
\hline Median $5.4^{\star *}$ & $100 / 285$ & 1.79 (1.17 to 2.72$)$ \\
\hline
\end{tabular}

*Estimated from post-load blood glucose concentration (see method).

†Case number calculated from reported number of study population and cumulative incidence.

$\ddagger$ Pooled analysis of 30 cohorts (see table 1 ).

§Pooled analysis of seven cohorts (see table 1).

\Person year calculated from reported number of cases and incidence rate.

${ }^{\star \star}$ Estimated from haemoglobin A1c (see methods).

††Pooled analysis of five cohorts in US (see table 1). 


\section{Figures}

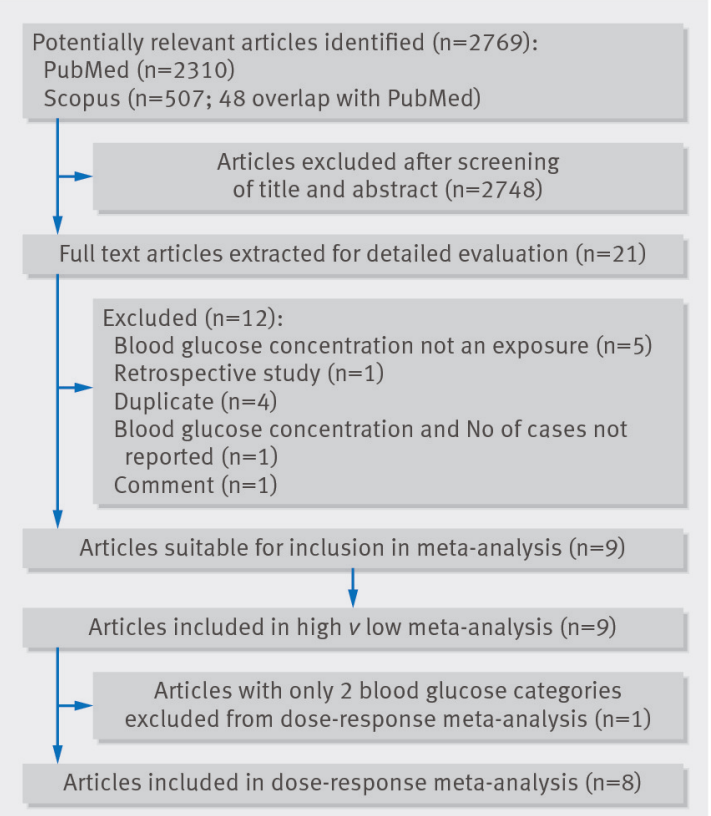

Fig 1 Flow chart of literature search for studies investigating association between blood glucose concentration and risk of pancreatic cancer

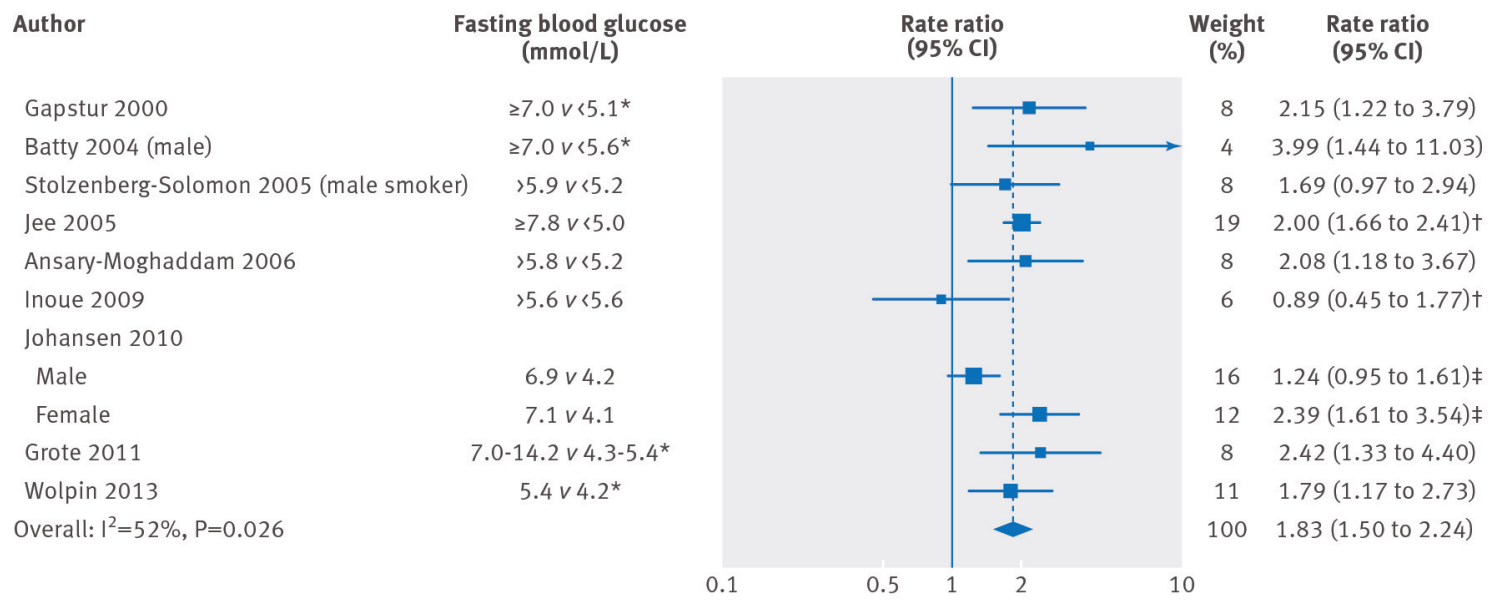

Fig 2 Summary rate ratio of pancreatic cancer, highest $v$ lowest blood glucose category. Weights from random effects analysis. *Estimated from reported post-load blood glucose or haemoglobin $A_{1 c}$ concentrations. †Pooled from rate ratios for men and women. ‡Pooling of rate ratios for men and women not feasible because categorisation of blood glucose differed between sexes 


\begin{tabular}{|c|c|c|c|}
\hline Author & $\begin{array}{l}\text { Rate ratio } \\
(95 \% \mathrm{Cl})\end{array}$ & $\begin{array}{c}\text { Weight } \\
(\%)\end{array}$ & $\begin{array}{c}\text { Rate ratio } \\
(95 \% \mathrm{Cl})\end{array}$ \\
\hline Gapstur 2000 & & 9 & 1.26 (0.99 to 1.60$)$ \\
\hline Batty 2004 (male) & & 4 & $1.08(0.72$ to 1.60$)$ \\
\hline Stolzenberg-Solomon 2005 (male smoker) & & 5 & 1.19 (0.84 to 1.68$)$ \\
\hline Jee 2005 & 三 & 36 & $1.06(1.00$ to 1.13$)$ \\
\hline Ansary-Moghaddam 2006 & & 3 & $1.48(0.98$ to 2.24$)$ \\
\hline Johansen 2010 & & & \\
\hline Male & & 17 & $1.02(0.88$ to 1.19$)$ \\
\hline Female & 16 & 10 & $1.30(1.04$ to 1.64$)$ \\
\hline Grote 2011 & in & 12 & $1.23(1.00$ to 1.49$)$ \\
\hline Wolpin 2013 & & 4 & $1.49(0.99$ to 2.24$)$ \\
\hline Overall: $\left.\right|^{2}=27 \%, P=0.206$ & $\dot{\alpha}$ & 100 & 1.14 (1.06 to 1.24$)$ \\
\hline 0.5 & 2 & 4 & \\
\hline
\end{tabular}

Fig 3 Summary linear trend of rate ratio per $0.56 \mathrm{mmol} / \mathrm{L}(10 \mathrm{mg} / \mathrm{dL})$ increase in fasting blood glucose. Weights from random effects analysis

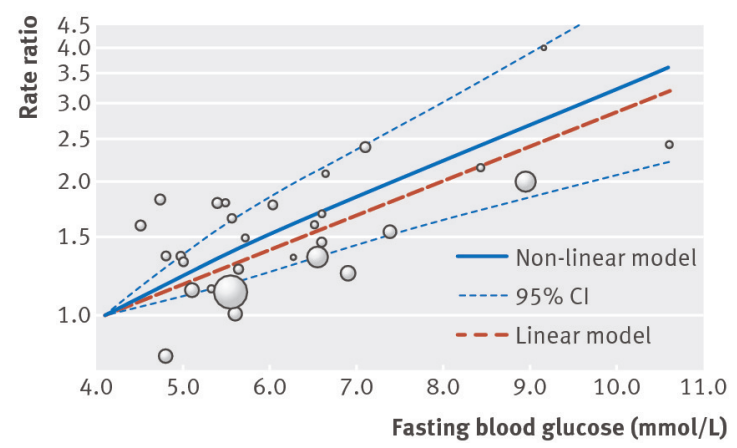

Fig 4 Dose-response relation between fasting blood glucose and rate ratio for pancreatic cancer, showing point estimates and $95 \%$ confidence interval for non-linear analysis and point estimates for linear analysis. Circles indicate adjusted rate ratios in individual studies; size of bubble is proportional to precision (inverse of variance) of rate ratio

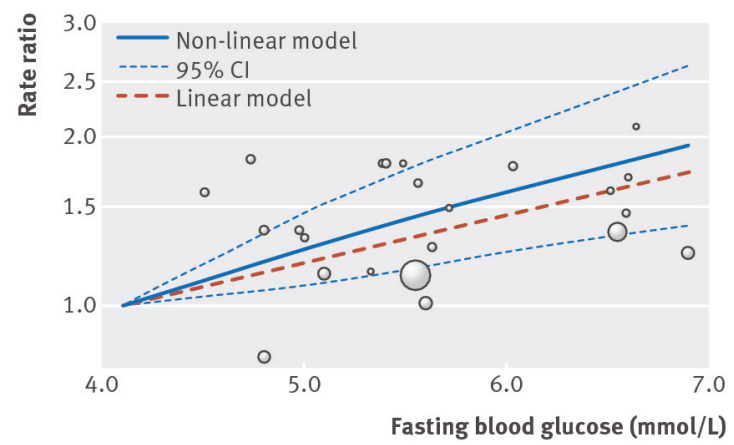

Fig 5 Dose-response relation between fasting blood glucose and rate ratio for pancreatic cancer, excluding categories with assigned fasting blood glucose concentration $>7.0 \mathrm{mmol} / \mathrm{L}$. Graph shows point estimates and $95 \%$ confidence interval for non-linear analysis and point estimates for linear analysis. Circles indicate adjusted rate ratios in individual studies; size of bubble is proportional to precision (inverse of variance) of rate ratio 